\title{
Effects of V-22 Blade Modifications on Whirl Flutter and Loads
}

\author{
C. W. Acree, Jr. \\ Aerospace Engineer \\ NASA Ames Research Center \\ Moffett Field, California
}

\begin{abstract}
A CAMRAD II model of the V-22 Osprey tiltrotor was constructed for the purpose of analyzing the effects of blade design changes on whirl flutter. The model incorporated a dual load-path grip/yoke assembly, a swashplate coupled to the transmission case, and a drive train. A multiple-trailer free wake was used for loads calculations. The effects of rotor design changes on whirl-mode stability were calculated for swept blades and offset tip masses. A rotor with swept tips and inboard tuning masses was examined in detail to reveal the mechanisms by which these design changes affect stability and loads. Certain combinations of design features greatly increased whirl-mode stability, with (at worst) moderate increases to loads.
\end{abstract}

\section{Nomenclature}

$C_{P} \quad$ rotor power coefficient

$C_{T} \quad$ rotor thrust coefficient

$M_{\text {tip }} \quad$ tip Mach number

$r$ radial station

$r_{s} \quad$ radial station at start of sweep

$R \quad$ rotor radius

$x_{m} \quad$ tip mass offset, positive forward

$\Lambda \quad$ sweep angle, positive aft

$\delta_{3} \quad$ kinematic pitch-flap coupling angle

ABT afterbody torsion

APY antisymmetric pylon yaw

AWB antisymmetric wing beamwise bending

AWC antisymmetric wing chordwise bending

AWT antisymmetric wing torsion

SPY symmetric pylon yaw

SWB symmetric wing beamwise bending

SWC symmetric wing chordwise bending

SWT symmetric wing torsion

hpp half peak-to-peak

\section{Introduction}

Tiltrotor designs are constrained by aeroelastic stability requirements, specifically by the need to avoid whirl flutter. With current technology, this requires very stiff, thick wings of limited aspect ratio, which limits cruise efficiency and maximum speed. The rotor design is also constrained in such areas as control-system kinematics. Numerous approaches to improving the whirl-mode airspeed boundary have been investigated, including active stability augmentation (Ref. 1) and aeroelastic tailoring of wings and rotors (Refs. 2-4). The research reported here applies the purely passive approaches of sweeping the outboard blade sections and moving tip balance weights forward.
Improving proprotor whirl-mode stability margins is an ongoing research activity at NASA Ames Research Center. Previous publications presented results for the XV-15 (Ref. 5), and initial results for the V-22 (Ref. 6). The present paper includes results for an updated V-22 CAMRAD II model with a multiple-trailer free wake (Ref. 7) and other improvements, applied to rotors with swept tips and chordwise tip-mass offsets.

This paper begins with a discussion of the V-22 CAMRAD II model, followed by whirl-flutter predictions for the baseline V-22 rotor. Then follow discussions of rotor design modifications, including $\delta_{3}$ variations (to deliberately destabilize the baseline rotor) and idealized models of swept blades and tip-mass offsets. The most practical combination of design changes-swept tips with an inboard tuning mass-is examined in some detail for stability, and briefly for loads.

This paper also examines the mechanisms by which sweep and tip mass offsets affect whirl flutter. The paper concludes with suggestions for further research and associated model improvements.

\section{V-22 CAMRAD II Model}

The V-22 rotor is stiff in-plane with a gimbaled hub and $-15 \mathrm{deg}$ pitch-flap coupling $\left(\delta_{3}\right)$. The structure is mostly composite, with a coning flexure and blade-fold hinges. The aerodynamic sections start with a 36 -in chord at $5 \%$ radius, linearly tapering to a 22 -in chord at the tip. The taper is interrupted by a bump over the blade-fold hinge. Total effective blade twist is 47.5 deg over a 228.5 -in radius. The quarter-chord locus is swept about $1 \mathrm{deg}$ aft, with the quarter-chord line intersecting the pitch axis at $75 \%$ radius.

The V-22 tiltrotor was modeled with CAMRAD II Release 4.1 (Ref. 8). Considerable effort went into modeling the V-22 yoke and grip (Fig. 1). The V-22 hub comprises three composite arms, or yokes, connected to the shaft by a constant-velocity joint. The yokes gimbal as a unit, but do 
not pitch with the blades. Centrifugal loads and flap and lag moments are carried by the yokes. Pitching moments, hence control loads, for each blade are carried by a hollow pitch case ("grip") that surrounds the yoke and pitches with the blade. The blades are attached to the outer ends of the grips.

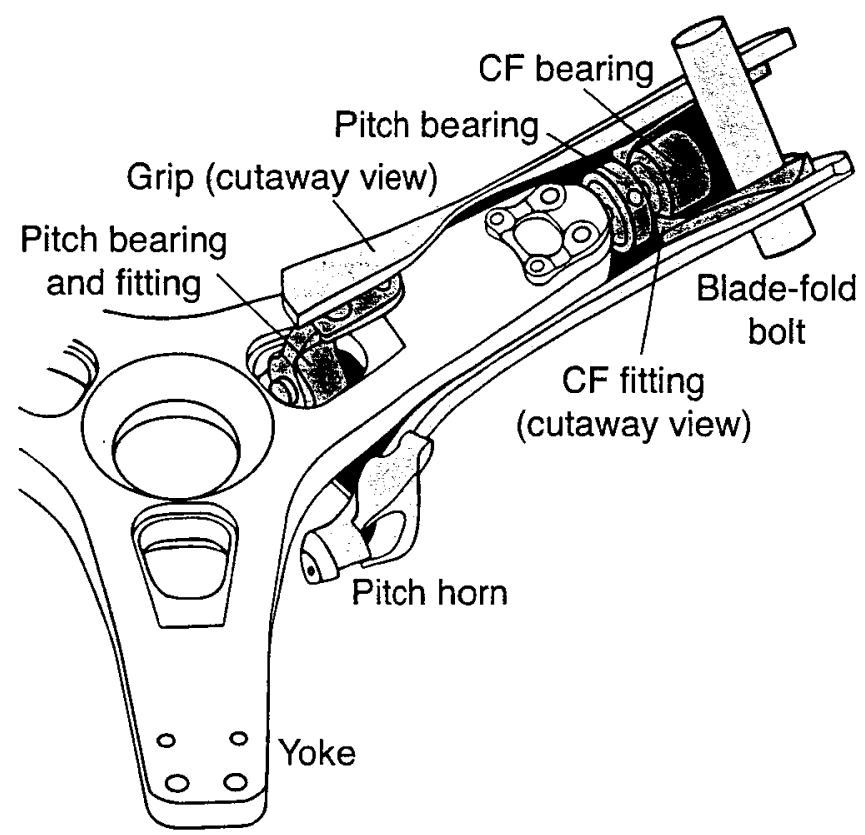

Fig. 1. V-22 rotor yoke and grip; pitching components are shaded.

Each yoke is much less stiff in flap than in lag, such that it constitutes a coning flexure; the zero-load precone is 2.75 deg. The large lag stiffness places the first lag frequency above $1 / \mathrm{rev}$ for all flight conditions, so that the rotor is by definition stiff in-plane.

The grip is connected to the yoke by a series of elastomeric bearings that accommodate the large changes in pitch needed between hover and high-speed flight. Two pitch-change bearings at (approximately) the inboard and outboard ends of the yoke accommodate blade pitch and transmit shear loads from the grip to the yoke. A separate bearing restrains the blade against centrifugal loading. The elastomeric bearings allow a small amount of in-plane and out-of-plane cocking of the grip with respect to the yoke, in order to accommodate flexing of the yoke as the coning angle changes.

The V-22 CAMRAD II model is based on four sets of data:

1. Rotor structural data provided by Bell Helicopter Textron (Ref. 9), originally developed for Bell Helicopter's Myklestad program.
2. Rotor aerodynamic data, in the form of $\mathrm{C} 81$ tables, also provided by Bell Helicopter. The C81 tables are based on wind-tunnel test data of the rotor airfoils (Ref. 10).

3. Airframe geometry, converted from an earlier CAMRAD/JA model developed by Boeing Helicopters.

4. Airframe modal data, generated by MSC/NASTRAN SuperElement models of the V-22, provided by Bell Helicopter (Ref. 9; see also Ref. 11).

Additional data (unpublished) were provided by David A. Popelka and Jim C. Narramore of Bell Helicopter. The rotor modeled is the Engineering and Manufacturing Development (EMD) version.

Further details of the model are discussed in the following paragraphs, which apply to whirl-flutter calculations. Loads analyses use a free wake model and other features, which are discussed in the Loads section of this paper.

\section{Rotor model}

The CAMRAD II model of the V-22 is documented in detail in Ref. 12. A summary of key features follows.

The hub/yoke model has a rigid hub extending to the inboard pitch bearing, and two elastic beam elements, representing the yoke, between the bearings. The blade model has four elastic beam elements, starting at the inboard pitch bearing: the grip is modeled as a single element, and the rest of the blade with three elements. The outermost blade element spans the swept section.

The blade model has 17 aerodynamic panels, each with collocation points at $1 / 4$ and $3 / 4$ chord. This is more panels than would normally be used for whirl-flutter calculations, but a finer distribution is appropriate to capture the effects of blade sweep. Uniform inflow is adequate for whirl-flutter analyses and was used for all stability calculations.

Release 4.1 of CAMRAD II provides multiple options for dual-load-path models. The option most appropriate for modeling the V-22 grip/yoke assembly specifies the flexbeam/blade connection (via the snubber) in flexbeamoriented axes. Using this model, the blade frequencies were matched to Myklestad predictions, adjusted for test data.

The blade-frequency data are for a non-rotating test of the entire V-22 rotor, with all three blades but without the gimbal, drive train, or control system (Ref. 13). Therefore, the root boundary conditions are considerably different than those for the complete aircraft. Moreover, the test did not use production blades. To provide better criteria for blade frequency comparisons, error ratios between Myklestad nonrotating predictions and the test data were calculated, then the Myklestad rotating predictions were corrected by the same ratios to generate new target frequencies. For example, the lag mode at $6.79 \mathrm{~Hz}$ (Myklestad prediction) was 
increased by $2.00 \%$ to get a target frequency of $6.93 \mathrm{~Hz}$, and the effective lag stiffness of the yoke was adjusted to match.

\section{Control-system stiffness}

CAMRAD II provides for separate collective and cyclic non-rotating stiffnesses, referenced to the swashplate, plus a rotating pitch-link stiffness. The complete kinematics of the swashplate, pitch link and pitch horn are modeled. However, CAMRAD II does not model any local nonlinearities in the swashplate and actuator stiffnesses that may arise as the actuators extend and retract. CAMRAD II computes the collective and cyclic frequencies together, using the total effective pitch stiffness as determined by the control-system kinematics. The swashplate actuators are assumed to be coupled to the transmission case, so that the swashplate motion is determined by the airframe mode shapes at the transmission, not the hub (Ref. 6).

Figure 2 schematically illustrates the CAMRAD II control-system model. The swashplate is assumed to be rigid, but can translate along the rotor shaft for collective inputs, and pivot for cyclic inputs. There is a cyclic spring, as shown, plus a linear spring for collective. CAMRAD II can have separate lateral and longitudinal cyclic spring rates, but these were made equal in the present $\mathrm{V}-22$ model.

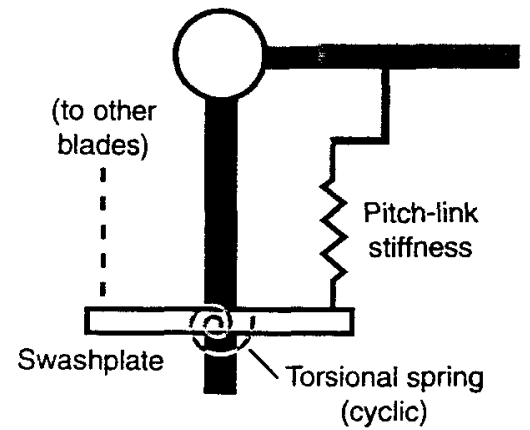

Fig. 2. Control-system model with separate rotating- and fixed-system stiffnesses.

\section{Airframe model}

To calculate aeroelastic stability, CAMRAD II couples externally generated wing/pylon modes to an internally generated dynamic rotor model (Ref. 8). The wing/pylon modes were generated by a three-dimensional NASTRAN shell model (about 68,000 elements), with frequency adjustments based on flight- and ground-test data (Ref. 9). The structural damping of each mode was adjusted in accordance with test data, then increased by a constant value to approximate the effects of wing aerodynamic damping as given in Ref. 9.

The drive-train model included the engine and gearbox rotational inertias, drive-shaft and cross-shaft flexibilities, but no governor.

\section{Trim and flutter models}

Except where noted, the model was trimmed to zero power (windmill state). Zero power is typically the least stable flight conditions for tiltrotors, and the drive train affects certain boundary conditions for blade modes. The V-22 has a flapping controller that minimizes flapping in flight; this was modeled in CAMRAD II simply by assuming axisymmetric, axial flow and by trimming to zero power with collective. This automatically yielded zero flapping. A further simplification was to trim the rotor to zero power in level flight and the airframe to zero angle of attack, which essentially ignored airframe aerodynamics. Given the assumptions of axisymmetric flow and zero power, there was little to be gained by explicitly trimming the airframe. The automatic flight control system was not needed for trim and was not modeled. The rotor was trimmed to $332 \mathrm{rpm}$ at $7500 \mathrm{ft}(2300 \mathrm{~m})$ altitude to match the Aeroelastic Stability Analysis of Proprotors (ASAP) predictions in Ref. 9.

For trim, blade deflections are calculated using nine flexible degrees of freedom per element (the CAMRAD II default; see Ref. 8). Flutter calculations included a gimbal for each rotor, nine airframe modes, and seven drive-train modes. The blade flutter model used 12 dynamic modes per blade (the 12 lowest frequencies, up to $174 \mathrm{~Hz}$, or $31 / \mathrm{rev}$ uncoupled). The airframe modes included wing beamwise and chordwise bending, wing torsion, and pylon yaw, separated into symmetric and antisymmetric modes, and the afterbody torsion mode; the airframe frequencies ranged from 2.9 to $8.6 \mathrm{~Hz}$. The drive-train model included separate rotor-, engine- and interconnect-shaft torsional flexibilities plus rotor, engine, shaft and gearbox rotational inertias.

\section{Baseline Predictions}

Figures 3-6 show the whirl-flutter predictions for the baseline CAMRAD II model. Frequency and damping are plotted against airspeed for symmetric and antisymmetric modes. These predictions are for level flight at zero power. Tracking the modes is problematic at high speeds because of the strong modal couplings, including multiple frequency crossings. Fortunately, the ambiguities are limited to highfrequency modes that do not determine the flutter boundary; therefore, no significant effort was made to track and label the modes. Furthermore, damping predictions above 400 knots are of limited accuracy because of limitations of the airfoil tables (Refs. 6 and 12).

Gimbal modes are also shown in Figs. 3 and 4 to indicate their effects on the symmetric wing beamwise bending (SWB) and antisymmetric chord bending (AWC) modes. The gimbal modes are highly damped and well off the scales of Figs. 5 and 6. The peak in the AWC mode (Fig. 6) is caused by an interaction with the gimbal mode. 


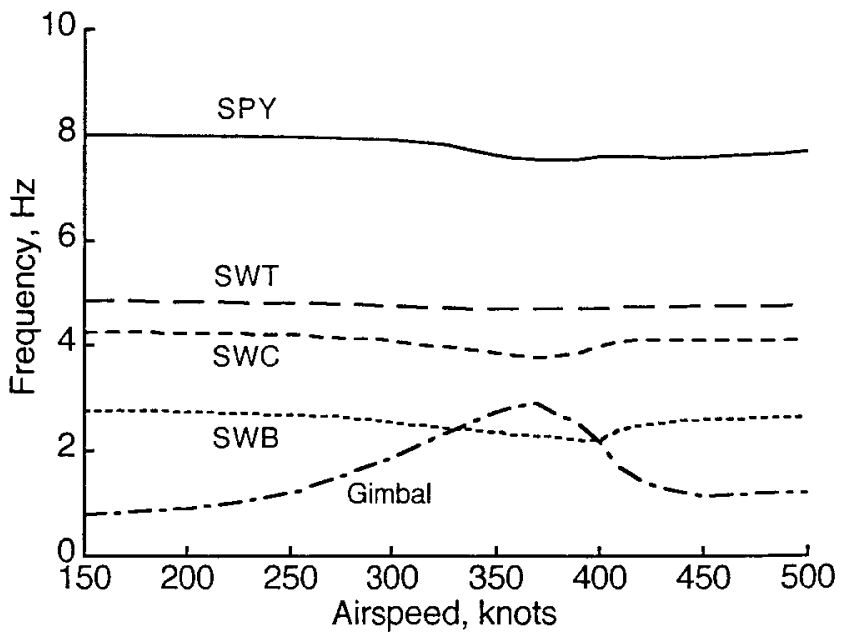

Fig. 3. Predicted frequencies of the V-22 symmetric wing/pylon modes.

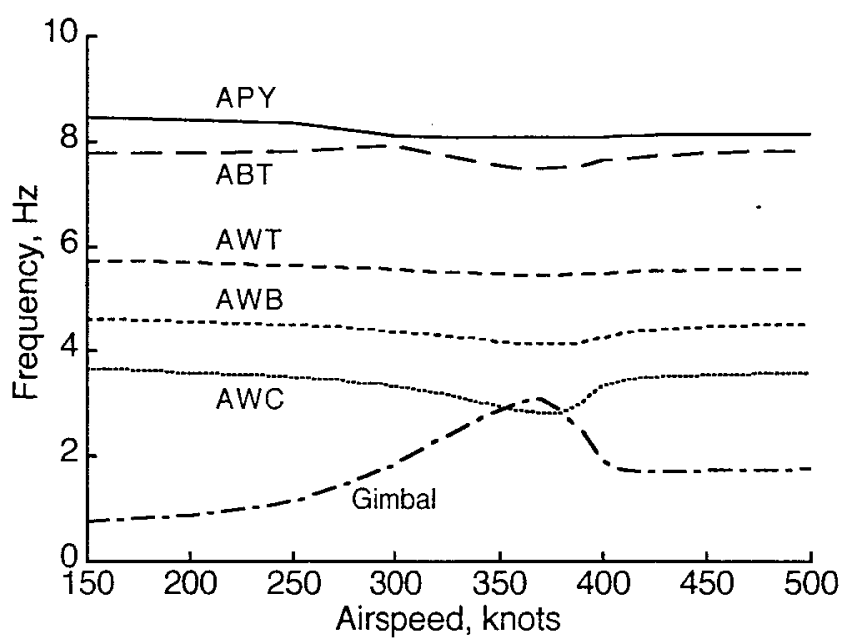

Fig. 4. Predicted frequencies of the V-22 antisymmetric wing/pylon modes.

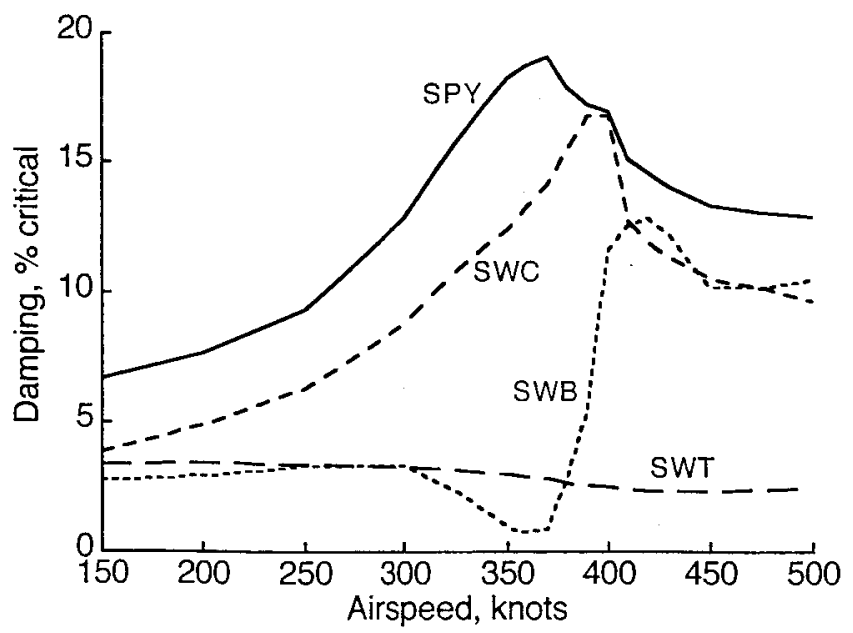

Fig. 5. Predicted damping of the V-22 symmetric wing/pylon modes.

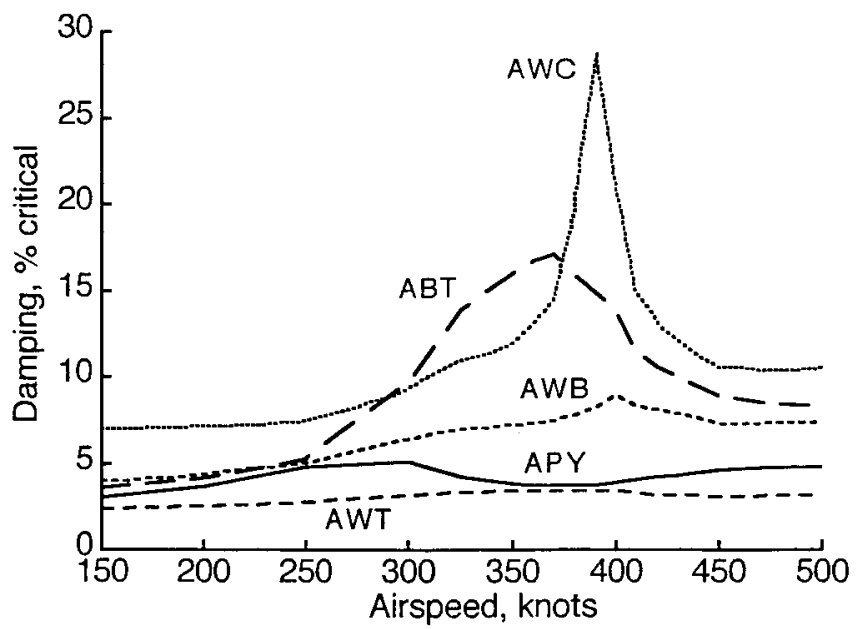

Fig. 6. Predicted damping of the V-22 antisymmetric wing/pylon modes.

All modes are stable at all airspeeds, and with one exception have favorable trends. The exception is SWB (Fig. 5 ), which is just barely stable at about 360 knots. The dramatic increase above this speed is caused by compressibility effects. If this minimum stability margin could be increased, it would relax important constraints on the rotor design. (The $\mathrm{V}-22$ rotor had to be redesigned as a result of inadequate stability margins, as measured during a wind-tunnel test (Ref. 14).) This is the primary motivation for the present research.

The SWB mode has the smallest stability margin within the V-22 flight envelope, so it is the appropriate mode against which to test the effects of model variations, as discussed in the following sections. Because zero-power trim has the lowest damping for critical modes within the flight envelope, it is appropriate for this study and was used for all predictions reported herein.

\section{Effects of Design Variations}

This section examines the mechanisms by which sweep affects whirl flutter. Broadly speaking, blade design changes can affect stability either by altering the forces and moments on the blade or by altering the dynamic response to those forces and moments. Detail mechanisms include (1) reduction of local lift curve slope, (2) alteration of unsteady loads, (3) effective mass droop at high pitch angles, (4) alteration of inertial reaction forces, (5) alteration of blade mode shapes and frequencies, and (6) aerodynamic coupling with torsional components of blade mode shapes. These are examined for a variety of idealized blade models, followed by a practical design. It will be shown that the last three effects are the most important. 
Whirl-mode stability is also affected by kinematic couplings between the blades, hub, and control system. Because the V-22 hub geometry is tightly constrained, improving stability by altering such couplings is unrealistic. Instead, altered kinematics were used to destabilize the baseline design, as explained immediately below.

\section{$\delta_{3}$ effects}

Because it is already stable, the baseline model (Figs. 3-6 is not convenient for analyzing the effects of rotor design on aeroelastic stability. The effects of such design changes can be nonlinear, so it is more appropriate to use a baseline that is moderately unstable than to further increase stability of stable modes. Although analyzing whirl flutter with a more flexible, hence less stable wing would be physically realistic, it would require significant changes to the V-22 NASTRAN model in order to generate consistent mode shapes. However, it is a simple matter to destabilize the rotor by changing the pitch/flap coupling $\left(\delta_{3}\right)$. As defined herein, positive $\delta_{3}$ causes nose-down pitching for upwards blade flapping. The $V-22$ has negative $\delta_{3}$, as showin in Fig. 7 .

For the present study, $\delta_{3}$ was always changed by adjusting the distance of the pitch horn from the flapping axis, so that the distance from the pitch axis remained constant. Such a modification does not affect the structure or aerodynamics of the individual blades, so its effects on aeroelastic stability are not confounded with those of the other design changes considered below.

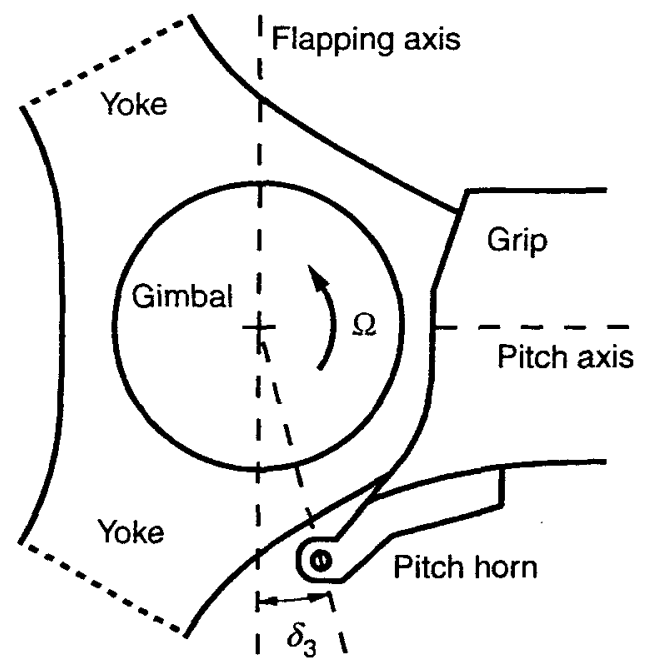

Fig. 7. Kinematics of V-22 hub and pitch horn, showing design $\delta_{3}$ of -15 deg.

Figures 8 and 9 show the effects on whirl flutter of changing $\delta_{3}$; only adversely affected modes are shown. The first lag mode rapidly becomes unstable for positive values of $\delta_{3}$ (Ref. 15), and larger negative values of $\delta_{3}$ are desirable for new rotor designs, so only negative values of $\delta_{3}$ were examined here. A reference airspeed of 300 knots was chosen to keep the rotor within its design envelope, but near the upper limit.

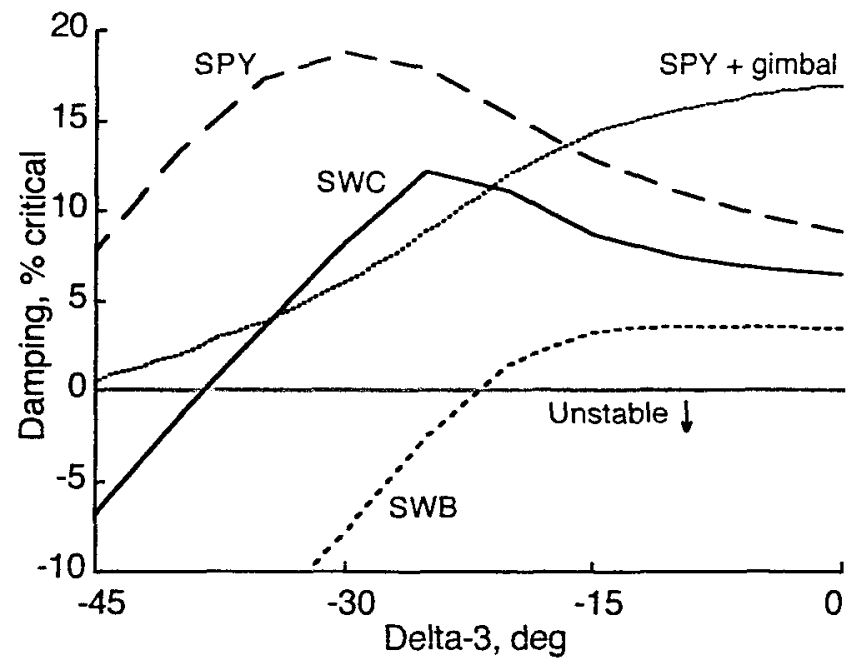

Fig. 8. Variation of damping with $\delta_{3}$ for the unmodified V-22 rotor at 300 knots. Only adversely affected symmetric modes are shown.

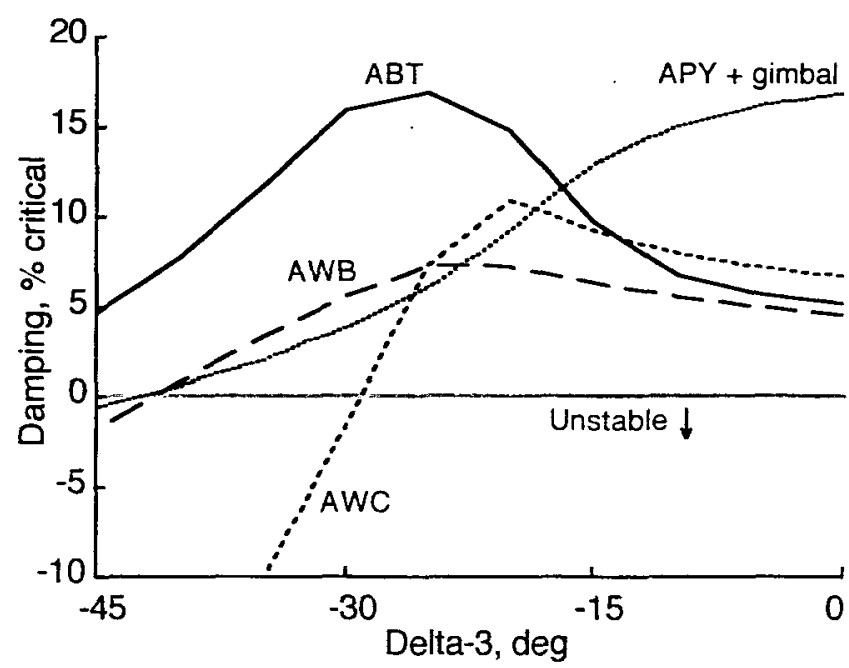

Fig. 9. Variation of damping with $\delta_{3}$ for the unmodified V-22 rotor at 300 knots. Only adversely affected antisymmetric modes are shown.

The trend in stability follows the classic pattern: the rotor remains stable until $\delta_{3}$ approaches $-20 \mathrm{deg}$, then the least stable mode (in this case, the SWB mode) rapidly loses stability as the magnitude of $\delta_{3}$ becomes more negative. At large values of $\delta_{3}$, the symmetric wing chord and pylon modes show similar trends towards instability as the SWB mode. The torsion modes vary only slightly and are not shown. AWC is the most sensitive mode, but at zero $\delta_{3}$ it is more stable than SWB, so it is not the critical mode. AWB and $\mathrm{ABT}$ show similar trends at high $\delta_{3}$. Two highly coupled modes, both involving primarily pylon yaw and progressive gimbal whirl modes, have nearly identical values, with nearzero stability at $-45 \operatorname{deg} \delta_{3}$. 
The $\delta_{3}$ values quoted here are for a level pitch horn; the actual value varies slightly with blade pitch. The design value of $\delta_{3}$ for the $V-22$ is $-15 \mathrm{deg}$, which provides an adequate stability margin. A value of $-30 \mathrm{deg}$ was chosen for the design studies discussed below. The challenge is to stabilize the SWB and AWC modes without degrading the other modes.

\section{Blade sweep}

To stabilize the rotor with $-30 \mathrm{deg} \delta_{3}$, combinations of blade sweep and tip mass offset were studied. Figure 10 shows several example blades derived from the V-22 rotor. For this rotor, the primary significance of sweep is the improved whirl-flutter boundary, not the reduced Machnumber effects. An offset tip mass is also shown; it is simply the existing balance weight moved forward from its normal position. The balance weight is normally located slightly inboard of the tip, as shown.

For this CAMRAD II model, blade sweep was invoked by sweeping the elastic axis and airfoil quarter-chord line by a sweep angle $\Lambda$, positive aft, starting at a radial station $r_{s}$. For these initial studies, $r_{s}$ was always $80 \% \mathrm{R}$. The tip mass was offset from its design location a distance $x_{m}$, positive forward. The entire mass was always moved. Tip mass offset is presented here in terms of equivalent sweep $\Lambda$, positive forward (Fig. 10c), for convenient comparisons to blade sweep.

For pure blade sweep (Fig. 10b), the tip mass was moved aft of the pitch axis with the rest of the blade so that it maintained the same position with respect to the local elastic axis. For pure tip-mass offsets (Fig. 10c), the tip mass was moved forward of the pitch axis with no other change to the blade structure.

Sweep was always calculated in the local chord plane, so it follows the blade twist. Tip mass offsets were also always in the local chord plane. The maximum sweep analyzed here is equivalent to less than one chord length at the tip.

Figures 11 and 12 show the effects of sweep and tip mass offsets on damping. The magnitudes of blade sweep and tipmass equivalent sweep are the same, but the signs are reversed. Most modes were little affected and are not shown. The least stable modes-SWB and AWC-were the most responsive to sweep and mass offset, which is encouraging. Note that the effects of sweep on damping are nonlinear, unlike the effects of tip mass offset. a)

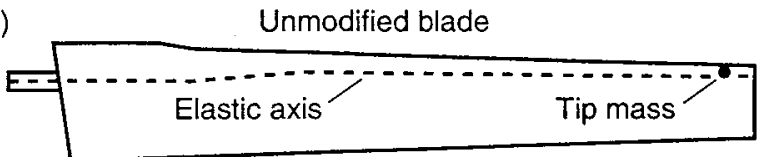

b)

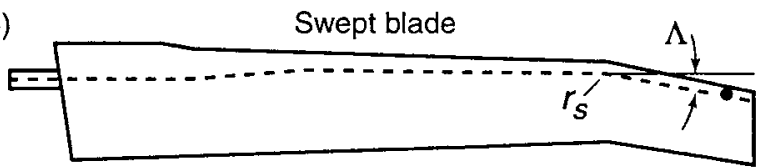

c)

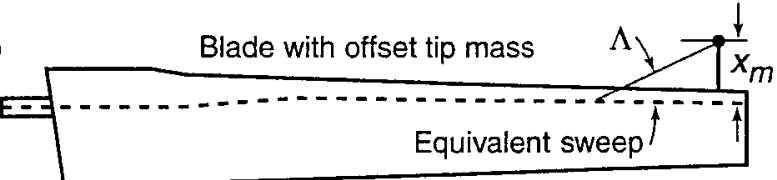

d)

Swept blade with fixed tip mass

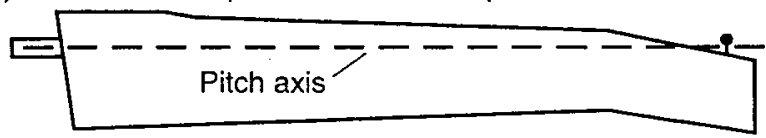

e)

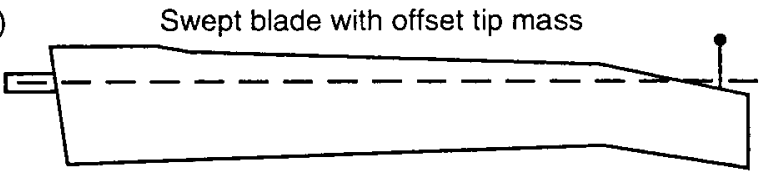

f)

Swept blade with inboard tip mass

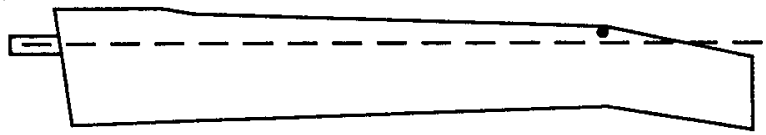

Fig. 10. V-22 rotor blade planform (47.5-deg twist not shown).

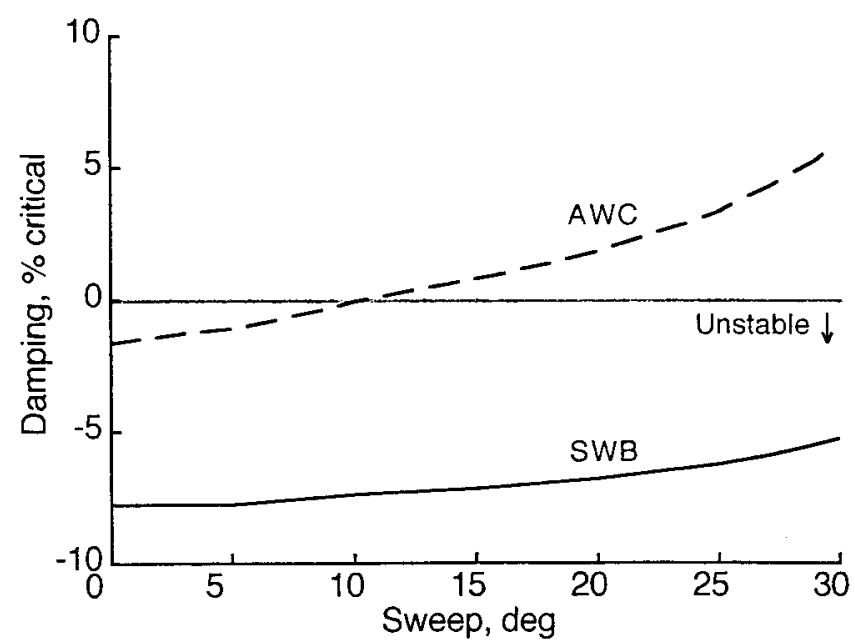

Fig. 11. Variation of damping with blade sweep at 300 knots with $-30 \operatorname{deg} \delta_{3}$ (see Fig. 10b). 


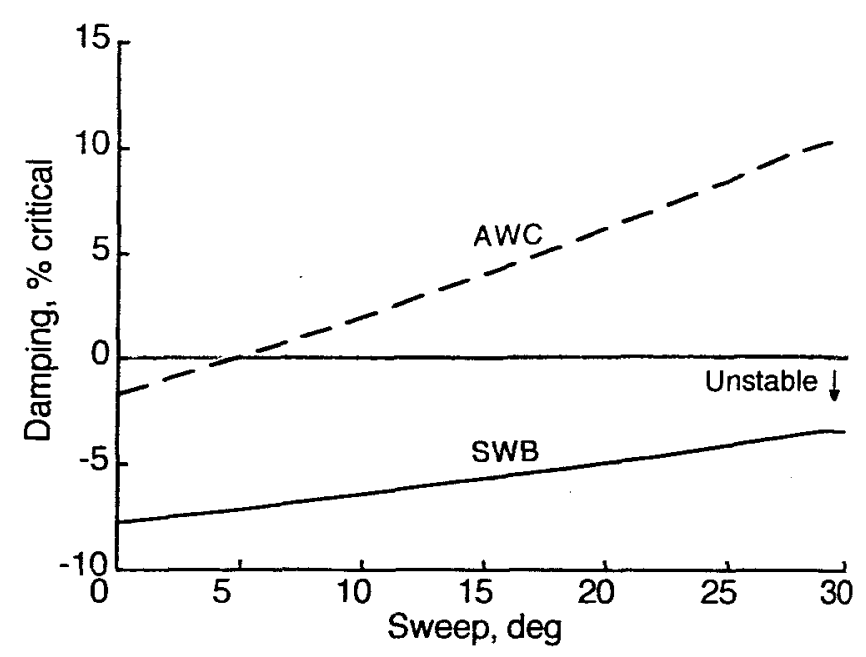

Fig. 12. Variation of damping with tip mass offet at $\mathbf{3 0 0}$ knots with $-30 \mathrm{deg} \delta_{3}$. Offset is calculated as equivalent sweep (see Fig. 10c).

Figure 13 illustrates the effects of combining sweep and tip mass offset. Sweep and mass offset were incremented by the same magnitudes but opposite signs (Fig. 10e). The response of the SWB mode is slightly nonlinear. The SWT mode damping decreases very slightly with sweep, so that the optimum value of sweep is about $27 \mathrm{deg}$.

Figure 14 shows the effects of sweep with the tip mass fixed at its original position with respect to the blade pitch axis, which is perhaps a more practical configuration (Fig. 10d). The damping is much improved compared to that with sweep alone (Fig. 11), although the SWB mode never becomes stable.

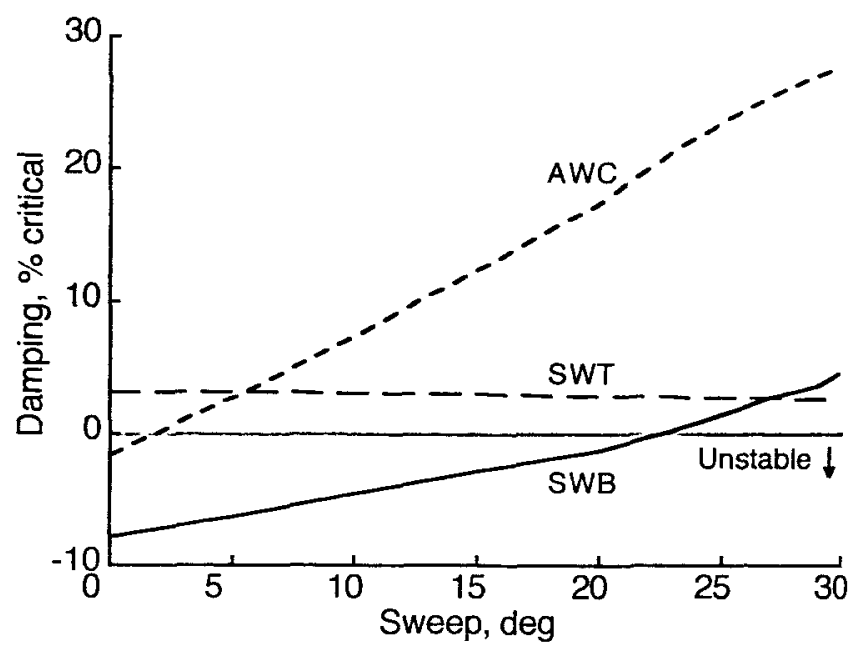

Fig. 13. Variation of damping with combined sweep and tip mass offset at 300 knots with $-30 \mathrm{deg} \delta_{3}$ (see Fig. 10e). Offet is calculated as equivalent sweep (Fig. 10c).

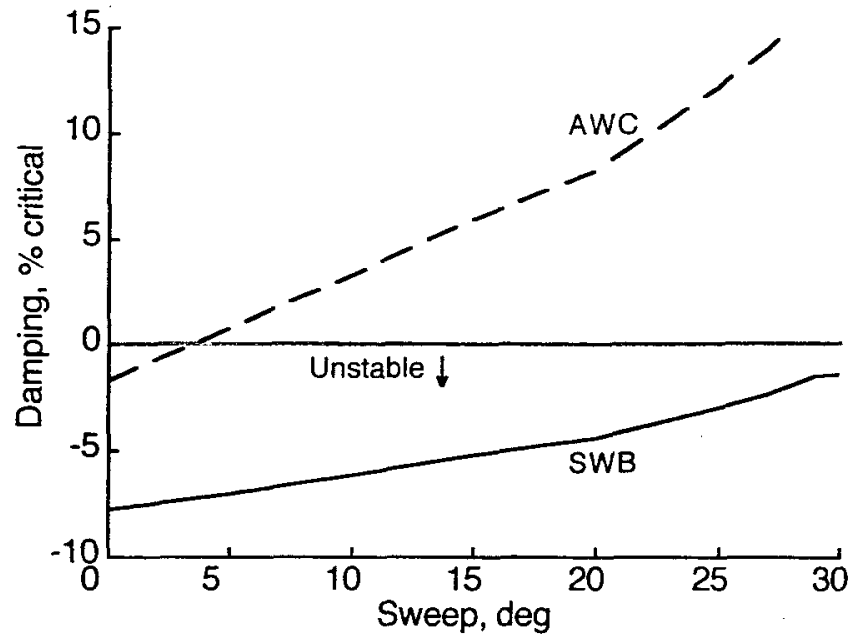

Fig. 14. Variation of damping with sweep and fixed tip mass position at 300 knots with $-30 \mathrm{deg} \delta_{\mathfrak{z}}$ (see Fig. 10e).

A more practical approach is to move the tip mass inboard, so that it is fully enclosed in the airfoil (suggested by David A. Popelka); it is here more properly called a tuning mass. For the predictions of Fig. 15, the tuning mass was moved to $0.8 R$ (the beginning of sweep) and positioned at the leading edge (Fig. 10f). The amount of mass was also doubled. With the standard mass value, the predictions were closely similar to those of Fig. 14. The SWB mode now becomes stable at 23 deg sweep. Because the SWT mode decreases slightly with sweep, the optimum value of sweep is $29 \mathrm{deg}$.

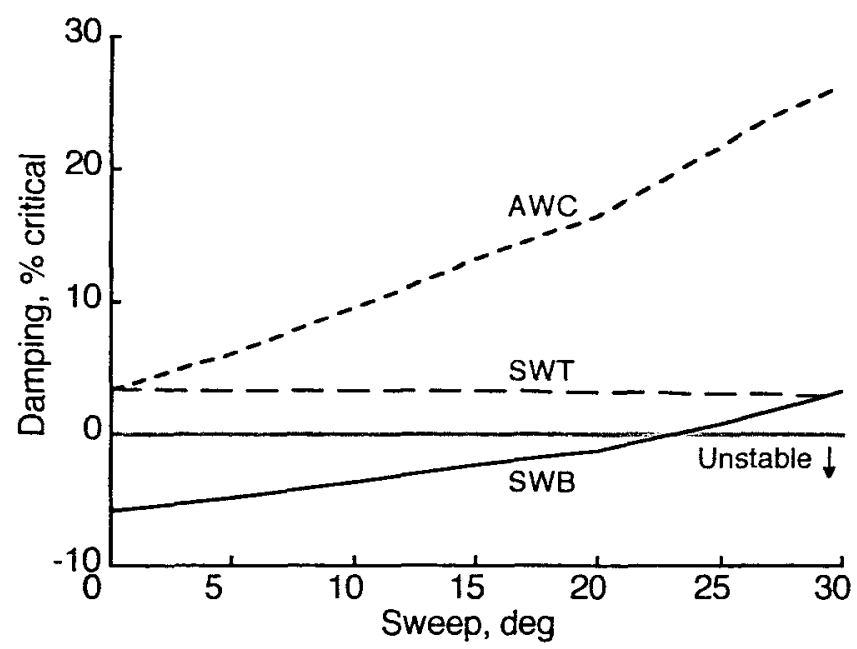

Fig. 15. Variation of damping with sweep for double tuning mass at inboard position at 300 knots with -30 $\operatorname{deg} \delta_{3}$ (see Fig. 10f). 
For ease of comparison, Fig. 16 replots the predictions for SWB mode damping. It emphasizes the effects of mass offset on both the sensitivity of damping to sweep, and on the nonlinearity of the responses. An offset tip mass would have to be placed on a boom extending from the leading edge. At large sweep angles, an inboard tuning mass at the leading edge is nearly as effective as a tip mass on a boom.

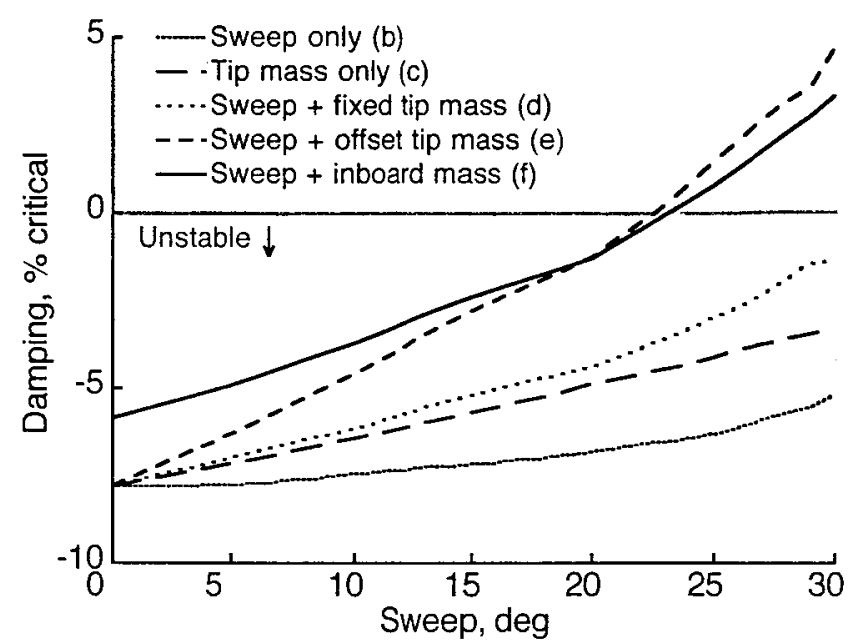

Fig. 16. Comparison of the effects of sweep and mass offset on the SWB mode at 300 knots with $-30 \mathrm{deg} \delta_{3}$ (labels refer to Fig. 10).

\section{Quasi-static couplings}

Figure 17 schematically illustrates how sweep and mass offset alter the perturbational forces on the blade. A swept tip moves the center of pressure aft of the pitch axis, creating a favorable (nose-down) moment for perturbational lift. An offset tip mass has an inertial reaction force ahead of the pitch axis, again creating a favorable moment. The blade mode shapes will be different for the two cases, leading to different net effects on stability.
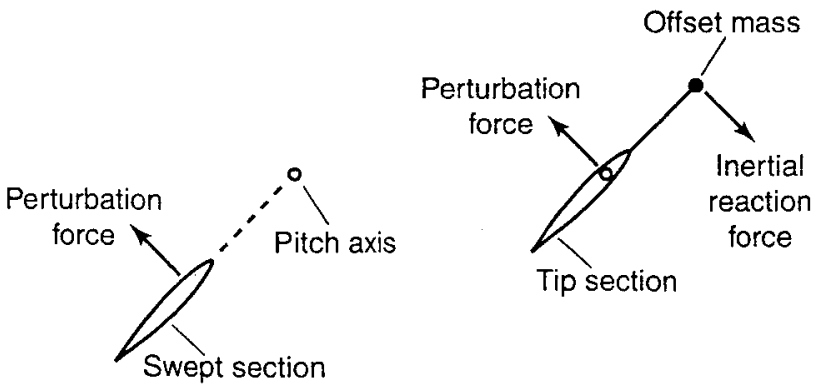

Fig. 17. Perturbation and inertial forces on a swept section and an offset mass, respectively.

Figure 18 shows the quasi-static modal coupling ratios for sweep and mass offsets, corresponding to Figs. $10 \mathrm{~b}$ and $10 \mathrm{c}$. For sweep, the pitch/lag coupling is always favorable (lag back, pitch down), but pitch/flap is unfavorable. For the range of sweep angles considered here, the pitch/flap coupling is never negative, but the slope becomes favorable above about $20 \mathrm{deg}$ sweep, which helps to explain the nonlinear variations of Fig. 11. For tip mass offsets, both couplings are always favorable, but much more so for pitch/flap than pitch/lag.

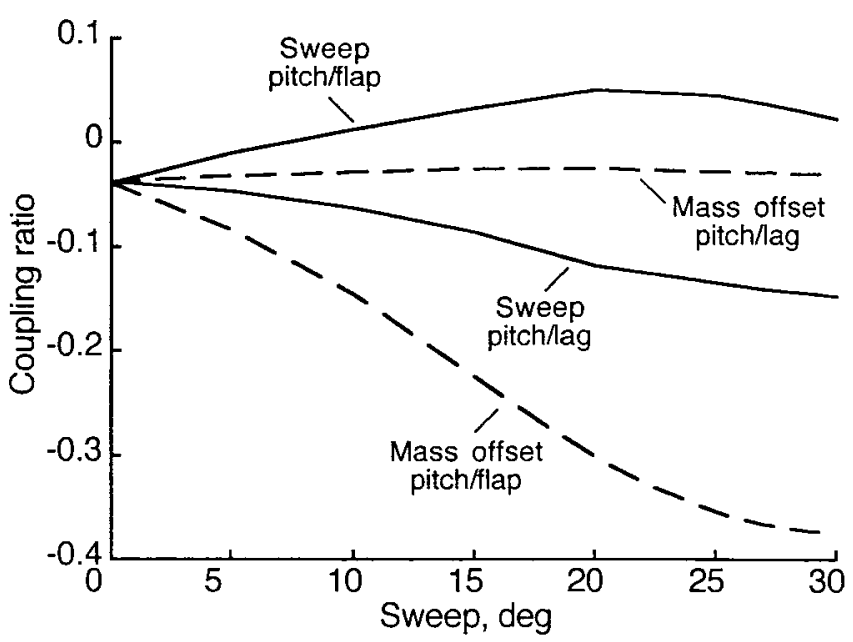

Fig. 18. Modal coupling ratios for blade sweep and tip mass offsets (Figs. 10b and 10c configurations).

\section{Aerodynamic effects}

CAMRAD II can separately model various aerodynamic and structural features, two of which are examined in more detail here: aerodynamic sweep versus offset, and unsteadyflow effects. The aerodynamic panels can be swept independently of the structure, and the effects of offset can be calculated independently of the effects of sweep angle. Figure 19 schematically illustrates the difference between panel offset and panel angle. The aerodynamic collocation points are centered spanwise on each aerodynamic panel. Only four collocation points and two swept panels are shown in the figure; the V-22 model used here has 17 total aerodynamic panels, six of which are swept.

Figure 20 shows the effects on the SWB mode of aerodynamic sweep only (no structural or inertial sweep), panel sweep angle only (no offset), and sweep offset without panel angles; the nominal full-sweep predictions (Fig. 11) are repeated for reference. Stability was also calculated for aerodynamic offset only (no structural sweep or aerodynamic panel angle), but even at this expanded scale, the curve is nearly indistinguishable from the aerodynamicsweep-only curve in Fig. 20 and so is not shown. It is clear that the effects of sweep on stability are dominated by the offsets of the aerodynamic panels, not by the angles of the panels. For reference, the maximum section Mach number at this speed is 0.7668 . 


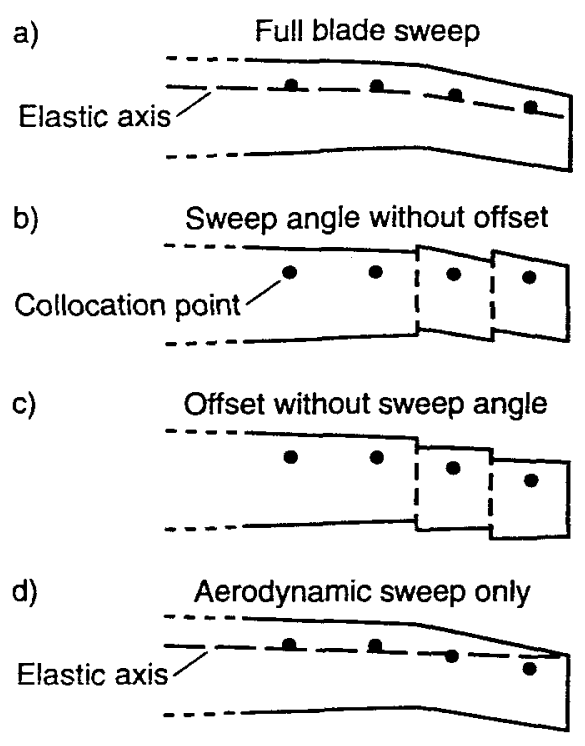

Fig. 19. Differences between blade sweep, aerodynamic sweep, aerodynamic panel sweep angle, and aerodynamic panel sweep offset (compare with Fig. 10).

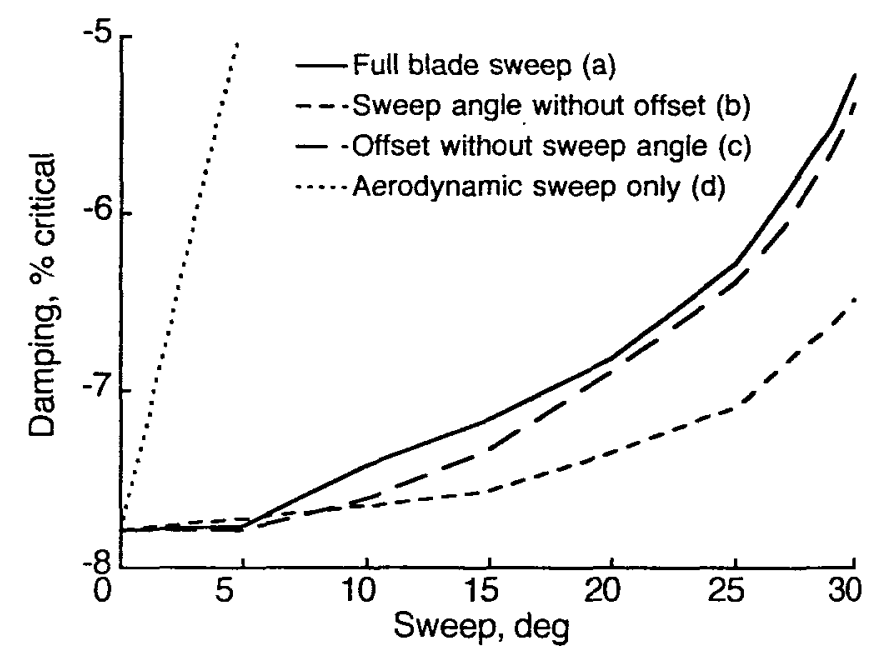

Fig. 20. Comparison of the effects of aerodynamic displacement vs. angle on the SWB mode at 300 knots with $-30 \mathrm{deg} \delta_{3}$ (labels refer to Fig. 19).

Further insight can be drawn from Figs. 16 and 20. Blade anhedral has been shown to improve whirl-flutter stability (Ref. 16). However, anhedral will include a mass offset, or droop, with respect to the tip path plane. Mass droop is equivalent to reduced precone and will be constrained by loads in hover and low-speed flight.

Because of the large change in collective angle between hover and airplane mode, the effective net mass droop will change significantly between flight modes. This will increase effective precone in hover and decrease it in airplane mode, thereby alleviating the problem. In Fig. 16, tip-mass offset is clearly stabilizing, even though the offset has a geometric component in the opposite direction to droop. Moreover, aerodynamic sweep without structural sweep is highly stabilizing (Fig. 20), and it has no mass droop by definition. The beneficial effects of sweep cannot be explained by effective mass droop.

The effects of unsteady aerodynamics were important for some modes. The most dramatic example is shown in Fig. 21 , for the SWB mode. This figure also shows the full effect on stability of idealized aerodynamic offset (no panel sweep or structural offset, Fig. 19c), which runs off the scale of Fig. 20. This idealized model is more sensitive to the effects of panel angle and unsteady aerodynamics than the full model, making the effects easier to discern in the plot. The curve for full aerodynamic sweep (with panel sweep but no structural sweep, Fig. 19d) is also shown; as in Fig. 21, the local sweep of the panels makes little difference.

Figure 21 shows that unsteady aerodynamics reduce stability for low and moderate values of offset, but for large offset, unsteady effects greatly increase stability. With full blade sweep (not shown), elimination of unsteady aerodynamics shifts the damping curves up with little change in trends with sweep. Significant effects were also seen for the least stable antisymmetric mode (AWC), and for tip mass offsets (not shown). In such cases, the trendlines were again simply shifted up a few percent when unsteady effects were removed, so that there was little effect on the sensitivity of stability to sweep or offset. Because unsteady aerodynamics have their greatest effect on the largest values of aerodynamic offset, which are already highly idealized design variations, unsteady effects could probably have been ignored without invalidating the analyses of other configurations. Nevertheless, unsteady aerodynamic effects were retained for all analyses reported here, excepting only those shown in Fig. 21.

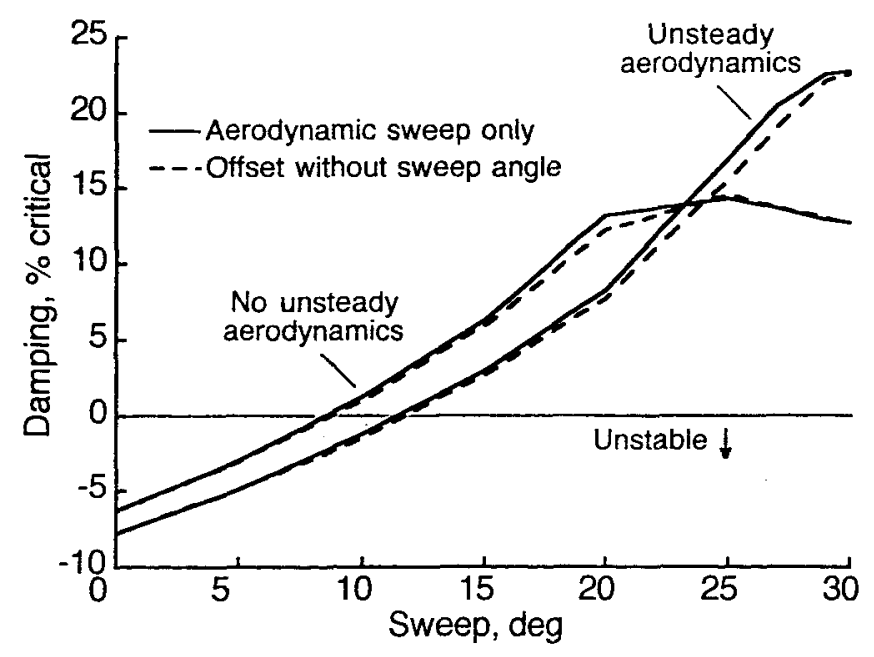

Fig. 21. Effects of aerodynamic displacement on the SWB mode, with and without unsteady aerodynamics, at 300 knots with $-\mathbf{3 0} \operatorname{deg} \delta_{3}$. 


\section{A practical example}

Several of the design variations covered so far are impractical, even physically impossible. One of the more effective and practical configurations, sweep with inboard tuning mass (Fig. 10f), was chosen for further study. With pure blade sweep, as in Fig. 10b, the tip mass is moved in the wrong direction for stability. If the mass is placed sufficiently inboard, it is unaffected by sweep, as in Fig. 10f. Such a design makes the effects of sweep on the blade mode shapes more evident, as illustrated below.

In order to focus attention on the key blade modes, the number of modes was systematically reduced until the stability trendlines for the SWB whirl mode showed significant departures from the full model (Fig. 15). The minimum number of blade modes was thereby determined to be four: the first flap and lag modes, the rigid pitch mode, and the second flap mode.

For SWB, the model with only four blade modes closely reproduced the trends of stability with sweep (Fig. 22), but with a slight offset. For AWC, the match was not as good, but because AWC is always more stable than SWB, and usually much more so, the simple model is adequate.

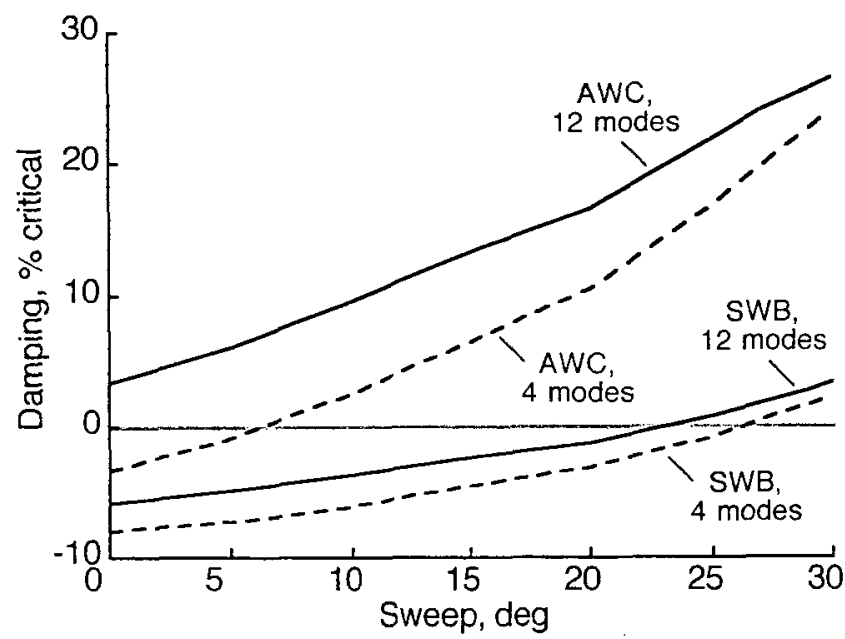

Fig. 22. Effects of simplified dynamic model on the most sensitive modes, for sweep with inboard tuning mass at 300 knots with $-30 \operatorname{deg} \delta_{3}$.

Adding the first elastic torsion mode (the seventh mode in order of frequency) brought the predictions into much closer agreement with the full model, but only by shifting the curves upwards without appreciably changing the trends. Moreover, the elastic torsion mode shapes were little affected by sweep. Although this indicates that the elastic torsion mode is essential for accurately predicting stability boundaries, it also implies that this mode is not important for explaining the physical mechanisms by which sweep affects stability.
Normalized mode shapes are plotted for the uncoupled blade modes at $332 \mathrm{rpm}$, as shown in Figs. 23-26. Only the four modes in the simplified model are shown. The figures also show the changes in the torsion mode shapes as sweep is varied in increments of $5 \mathrm{deg}$. Displacements (flap and lag) are scaled in feet; rotations (pitch/torsion) are scaled in radians. Flap is perpendicular to the hub plane (not the local beam axis), positive up (or forward, in airplane mode); lag is in the hub plane, positive aft (against the direction of rotation). Pitch/torsion mode shapes are positive nose up. The trimmed pitch angle at $0.75 R$ was $43 \mathrm{deg}$ for 0 -deg sweep.

For the modes shown here, flap and lag mode shapes were little affected by sweep. The differences are difficult, if not impossible, to discern at the scale of Figs. 23-26. For the sake of legibility, flap and lag mode shapes are shown only for 0-deg sweep.

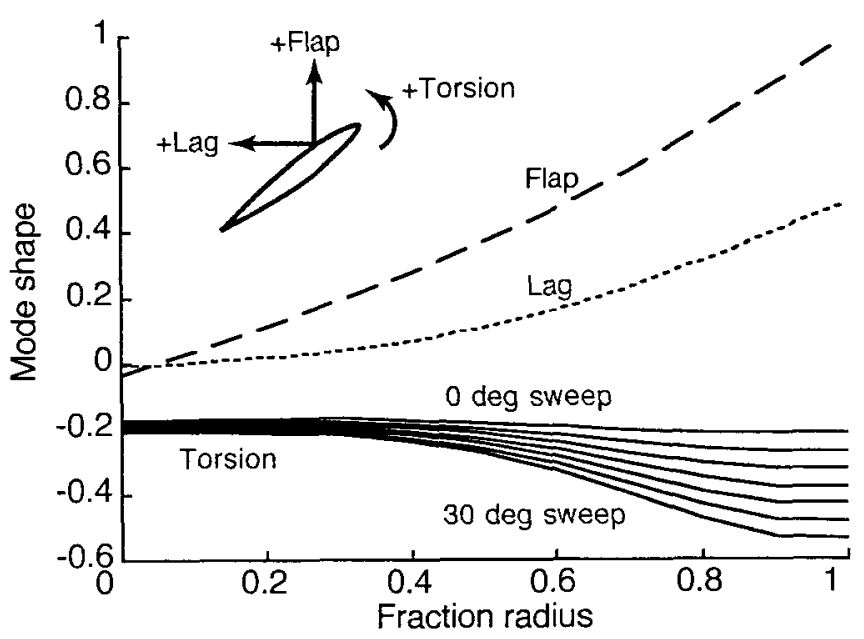

Fig. 23. Mode shapes for the 1st flap mode.

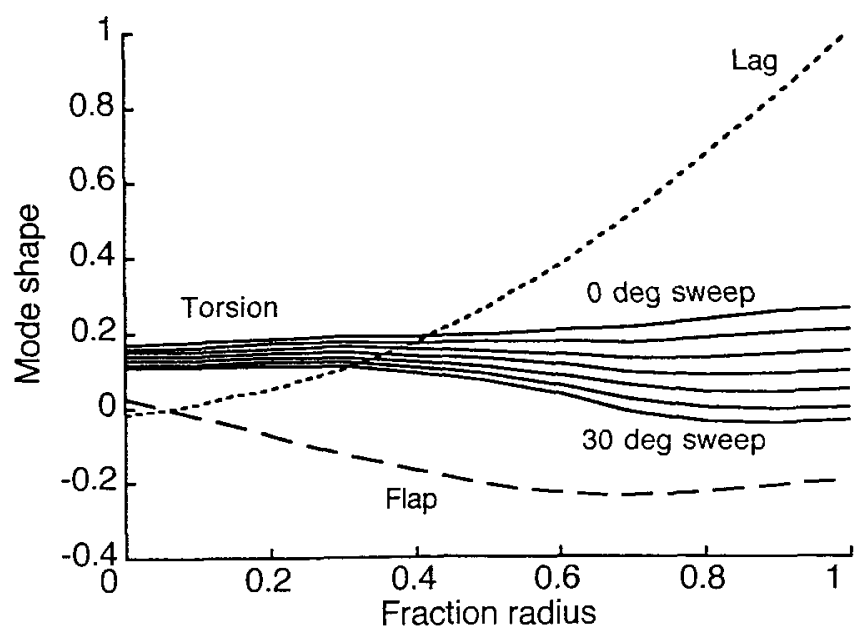

Fig. 24. Mode shapes for the 1st lag mode. 


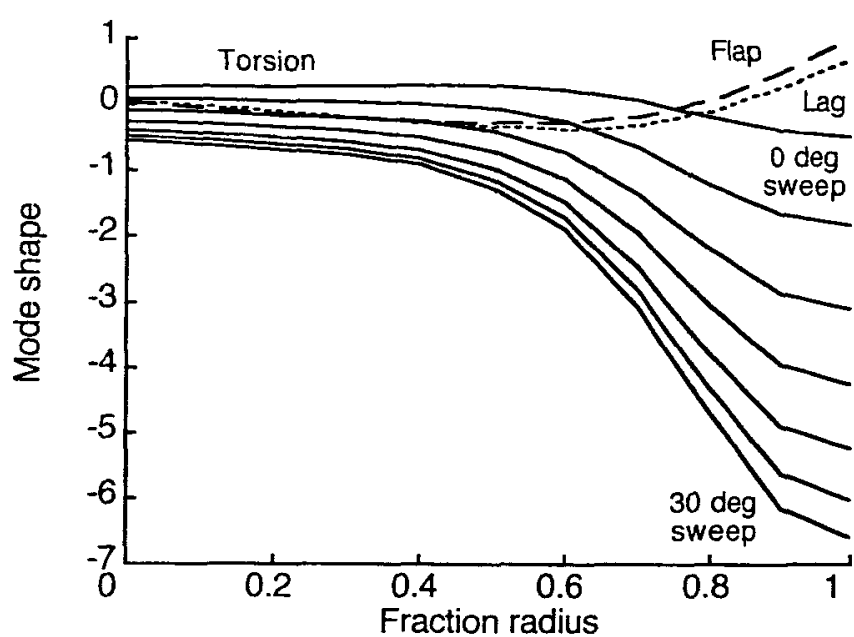

Fig. 25. Mode shapes for the 2nd flap mode.

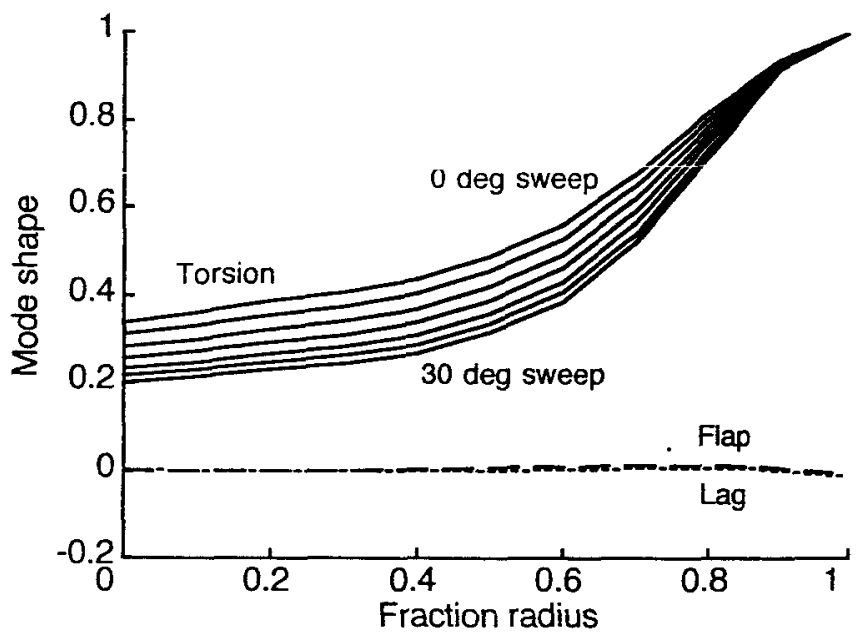

Fig. 26. Mode shapes for the 1st pitch/torsion mode.

Figure 27 shows the uncoupled blade mode frequencies at $332 \mathrm{rpm}$, plotted against sweep. The first flap and lag frequencies, at $1.22 \mathrm{~Hz}$ and $1.34 \mathrm{~Hz}$ respectively, vary only in the fourth decimal place and are not shown.

At the trimmed flight condition-300 knots, $332 \mathrm{rpm}$, and $7500 \mathrm{ft}$ altitude - the blade pitch angle at the tip is just over $35 \mathrm{deg}$. The mode shape of the first flap mode (Fig. 23) is almost perpendicular to the local chord at the tip. As sweep is increased, there is an increasingly negative torsional component. The associated reduction in local lift reduces the flapping motion and so stabilizes the mode. Similar effects can be readily deduced for the other flap/lag modes by inspection of Figs. 24 and 25.

It will be obvious that sweep helps to stabilize pitch/ torsion modes by creating a counter-acting aerodynamic moment for any torsional perturbation. Figure 26 suggests that sweep also changes the mode shape so as to enhance this effect. This can be better understood if the shapes of the first pitch/torsion mode are replotted as in Fig. 28, where the curves are offset to line up at zero radius for all sweep angles. For any given amount of torsion mode deflection, increasing sweep increases the effective pitch deflection at the tip, where the dynamic pressure is highest, thereby increasing the stabilizing moment.

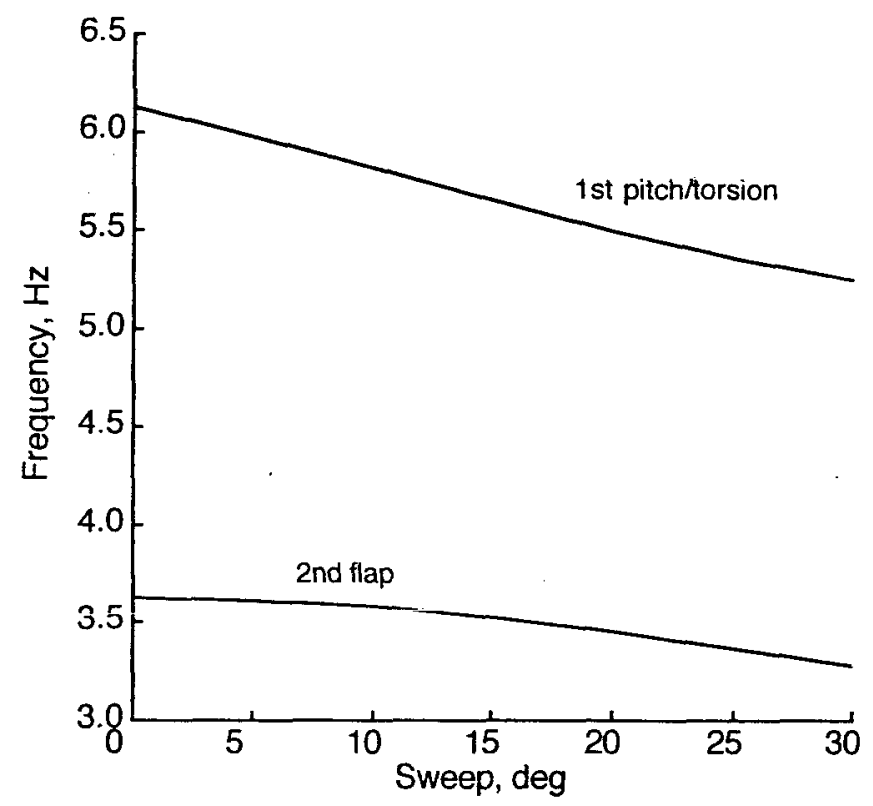

Fig. 27. Modal frequency variations with sweep.

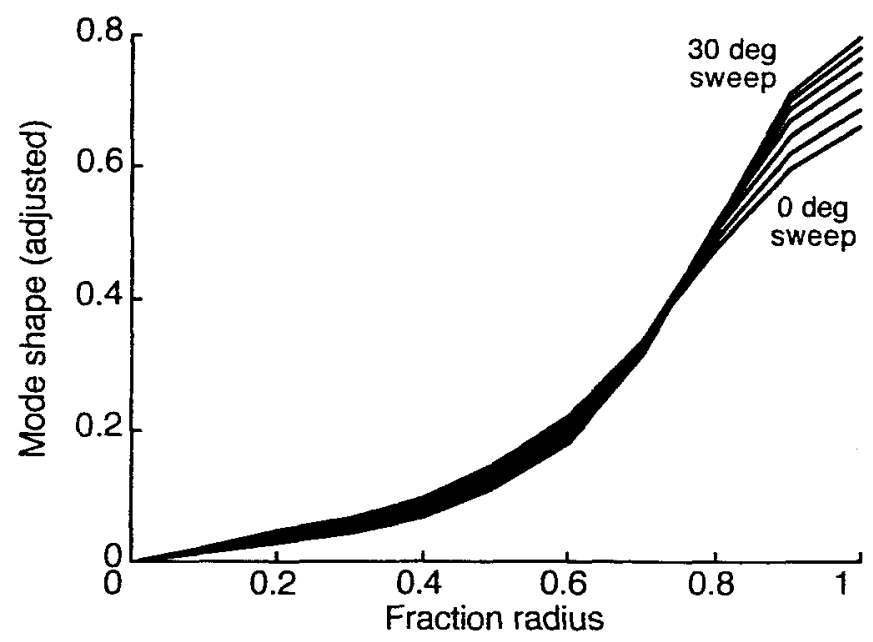

Fig. 28. Torsion mode shape for the 1st pitch/torsion mode, offset to force zero values at the root for all values of sweep.

These effects of sweep and mass offset on aeroelastic stability are directly analogous to those for swept, fixed wings, although here much complicated by the existence of a pitch mechanism and control-system flexibility, a gimbal and associated pitch/flap kinematics $\left(\delta_{3}\right)$, a flexible drive train, and the dynamics of the coupled rotating system. Their 
effects on whirl flutter are, of course, determined by the coupling between the fixed and rotating systems.

\section{Modal coupling effects}

As shown by Gaffey (Ref. 15), flap-lag stability at high inflow requires positive pitch/flap coupling (negative $\delta_{3}$ ) between the blade and control system. However, Figs. 23 and 25 imply that sweep and mass offset stabilize the rotor by introducing negative pitch/flap coupling. The apparent contradiction can be resolved by the following observations:

A major contribution to whirl-mode instability is the outof-plane component of the first lag mode (Fig. 24), which couples the lag mode to control system kinematics. The slopes of the flap and lag mode shapes have opposite sign at the root, which reverses the effective coupling. For positive $\delta_{3}$, the net coupling is lag back, pitch up, which is destabilizing. At high inflow, the rotor is very sensitive to this effect (Ref. 15), and negative $\delta_{3}$ is needed to stabilize the rotor. The values of sweep and mass offset examined here have little effect on the flap and lag mode shapes; indeed, the changes near the root are impossible to discern at the scale of Figs. 23-26. Therefore, the beneficial controlsystem couplings are unaffected.

For the lag mode (Fig. 24), sweep changes a mild, positive pitch/lag coupling to a stronger, negative pitch/lag coupling, which is stabilizing. Note also that the changes in pitch/torsion mode shapes are seen much more strongly at the tip than at the root (although Fig. 26 suffers from the normalization method used by CAMRAD II; Fig. 28 is more revealing)

The stabilizing effect of negative $\delta_{3}$ is seen as favorable shifts in the first flap and lag frequencies, which decouple the modes (Ref. 15). Sweep and mass offsets have negligible effects on these frequencies: the largest change seen here was less than $1 \%$. Therefore, the frequency separation is unaffected.

To summarize, for a rotor with a swept tip, the benefits of positive pitch/flap coupling at the root are retained for the rotor as a whole, while the benefits of negative pitch/flap coupling are realized near the tip, where the dynamic pressure is greatest.

\section{Loads}

The effects of rotor modifications on loads were investigated, to check for potentially serious changes. Table 1 summarizes the flight conditions analyzed. All conditions were derived from flight test data in Ref. 17, but do not necessarily match any particular test condition. All conditions except cruise were analyzed at sea level, with a rotor speed of $397 \mathrm{rpm}$. The cruise condition was $15,000 \mathrm{ft}$ and $333 \mathrm{rpm}$.
Table 1. V-22 flight conditions for loads analyses.

\begin{tabular}{lccc}
\hline \hline Flight mode & $\begin{array}{c}\text { Pylon angle, } \\
\text { deg }\end{array}$ & $\begin{array}{c}\text { Airspeed, } \\
\text { KTAS }\end{array}$ & $\begin{array}{c}\text { Power, } \\
\text { SHP }\end{array}$ \\
\hline Hover & 90 & 0 & 7050 \\
Helicopter & 85 & 60 & 3860 \\
Conversion & 75 & 80 & 3750 \\
Conversion & 60 & 100 & 4350 \\
Conversion & 30 & 140 & 4470 \\
Cruise & 0 & 275 & 7660 \\
\hline \hline
\end{tabular}

Loads were calculated with a multiple-trailer free wake model derived from that of Ref. 7. For trim, each blade had 12 dynamic modes (not just static deflections, as in the flutter analyses), and the rotor response was calculated with 10 harmonics.

Ideally, the loads analysis would use a complete model of the airframe aerodynamics and control system, with different aerodynamics and control phasing for each pylon angle and flap setting. However, no such models have yet been developed for the V-22 using CAMRAD II. Fortunately, the changes of interest apply only to the rotors, so an isolated rotor model is adequate. A single-rotor analysis also saves considerable computational time - a nontrivial issue with a free wake model.

For all loads analyses, the isolated rotor was trimmed to zero flapping (zero gimbal tilt). While this does not exactly match flight conditions, it is adequate to identify significant changes to loads and performance caused by blade sweep and other design modifications. It also establishes a more consistent rotor trim for all flight conditions, facilitating comparisons. There are thus four linked trim parameters: pylon angle, input as rotor shaft angle of attack; airspeed; rotor speed; and rotor power, input as one-half the total power in Table 1.

Because critical trim parameters were varied together, the trends of loads with airspeed or any other parameter should not be expected to be smooth or even monotonic. The data are plotted here as connected data points to simplify the figures and improve legibility. Caution should be exercised when attempting to interpret any apparent trends with airspeed.

Loads were calculated for the pitch links, grip $(0.05 R)$, yoke $(0.05 R)$, and blade $(0.35 R)$; in-plane (lag) and out-ofplane (flap) loads were calculated at each location (except the pitch links). Steady and vibratory loads were calculated as mean and half peak-to-peak (hpp) values.

Loads were calculated and compared for two rotors: the baseline V-22 rotor, and a rotor with 30-deg blade sweep and inboard tuning weights (the same rotor as in Figs. 22-28, 
but only with the largest value of sweep). Only the most extreme differences are presented here. The swept rotor had a -30 deg $\delta_{3}$ hub to match the stability calculations shown previously.

In order to prevent confounding the effects of rotor-blade design with the effects of $\delta_{3}$, loads for the baseline rotor were also calculated with a $-30 \mathrm{deg} \delta_{3}$ hub. Changes in loads are therefore attributable only to changes in the blade design. The effects of design changes on loads are summarized in Figs. 29 and 30 for $-30 \mathrm{deg} \delta_{3}$.

Figure 29 plots the pitch-link loads against airspeed for the two blade designs. Compared to the baseline blade design, the mean pitch-link load for the swept rotor is increased by $19 \%$ at 275 knots. This was the largest increase seen for any load. The amount of change due to $-30 \mathrm{deg} \delta_{3}$ was only $+0.1 \%$.

Figure 30 plots blade lag loads (at $0.35 R$ ) for the two blade designs. The half peak-to-peak loads varied very little and are not shown. The swept blades actually reduce the total load over most of the flight regime, and the worst-case load (about $4000 \mathrm{ft}-\mathrm{lb}$ at 50 knots) is about half the magnitude of the worst-case load for the baseline rotor. The load reduction at 275 knots is $88 \%$. This is the largest absolute difference seen for any load. (The amount of change due to $-30 \operatorname{deg} \delta_{3}$ was only $-4 \%$.)

However, the large load reductions may be merely fortuitous: as shown in Fig. 30, both the inboard tuning mass (without sweep) and sweep with the nominal tip mass (Fig. $11 \mathrm{~b}$ ) make the lag loads worse, but shifted in opposite directions relative to the baseline. The near-zero load at 275 knots may be only a coincidental canceling of the two effects. Nevertheless, the results are highly encouraging.

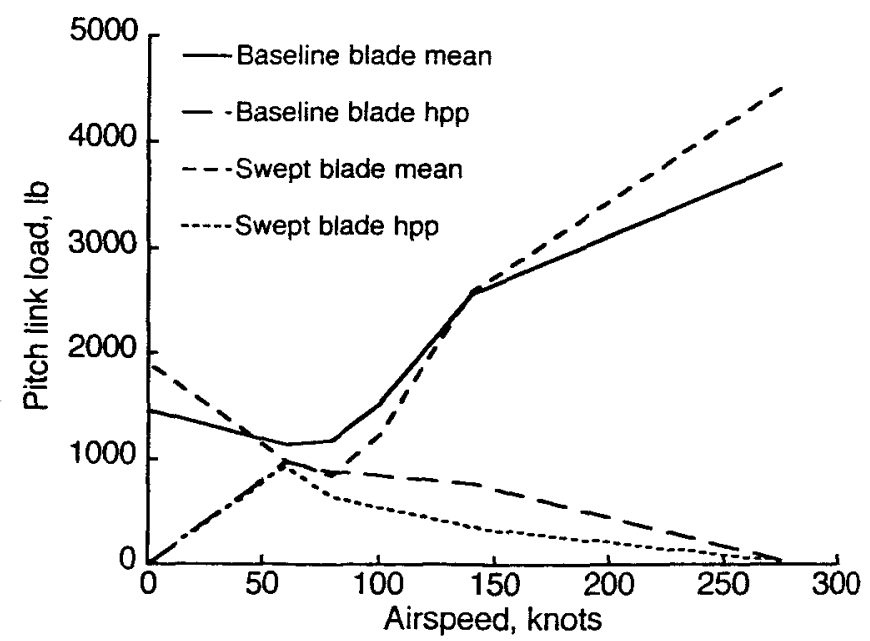

Fig. 29. Pitch link loads for the baseline and swept rotors.

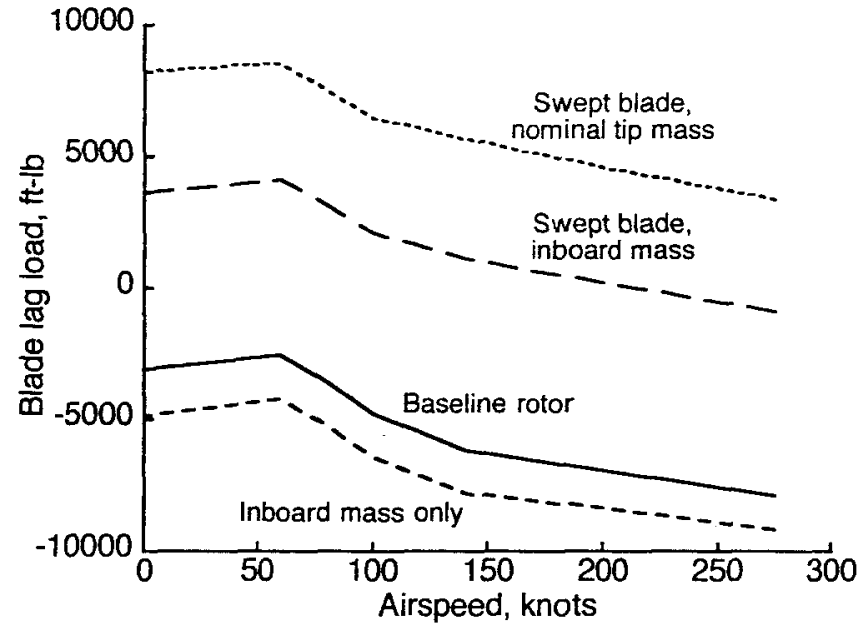

Fig. 30. Mean blade lag loads for the baseline and swept rotors, and for an inboard tuning mass.

The effects on performance were also examined, using the same isolated-rotor model as was used for loads. Because the rotor was trimmed to power without an airframe aerodynamic model, figure of merit (at hover) and propeller efficiency (at 275 knots) were used for comparison. The differences were minor, but positive: compared to the baseline rotor (with $-30 \mathrm{deg} \delta_{3}$ ), the swept rotor improved figure of merit from 0.79 to 0.80 for $M_{t i p}=0.709, C_{T}=$ 0.0137 , and $C_{P}=0.00143$; propeller efficiency improved from 0.84 to 0.85 for helical $M_{\text {tip }}=0.766, C_{T}=0.00500$, and $C_{P}=0.00418$. The beneficial effects of sweep on performance at high Mach numbers (Ref. 18) would not be expected to come fully into play at the airspeeds examined here. It is sufficient that there be no adverse effects, as was the case.

\section{Research Recommendations}

Further efforts are recommended in three areas: research into the physical mechanisms by which sweep and mass offsets affect stability, improved designs to maximize stability, and further development of the V-22 CAMRAD II model.

Although the results presented here provide a plausible explanation of the role of mode shapes in enhancing the stability of swept-bladed rotors, the explanation is not definitive. The current rotor model is too complicated for efficient numerical examination of pitch/flap/lag coupling and other effects: too many modes are required, both for the rotor and for the airframe, to adequately characterize the system response. Direct examination of the flutter matrices or the eigenvectors is appropriate, but would require much smaller matrices, hence a much simpler model, to be practical. 
The relative contributions of aerodynamic and inertial effects were only inferred, not directly calculated. Also, sweep and mass offsets were always in the local chord plane, so there was no direct examination of the relative effects of sweep versus mass droop. These effects may all be expected to interact with each other.

It is fundamentally difficult to separate the relative contributions of the different elastic deformations and couplings. Even for an unmodified rotor, blade elasticity is intimately involved in whirl-mode instability in the first place. Therefore, the effects of blade elasticity cannot be fully decoupled from those of sweep. Similarly, the effects of tip-mass inertia cannot be studied in isolation without changing the underlying aeroelastic phenomena being explored. However, such effects can be inferred from parametric blade-design studies, such as those presented here. The present V-22 model does not lend itself to efficient exploration by such methods, so a new model is being developed specifically to support further studies of whirl flutter. It need not be as accurate as the model used here, as long as it captures the general features of V-22 behavior.

Even without further insight into the physical mechanisms, improvements in blade design should be possible with conventional optimization techniques. Although true optimization is beyond the scope of the present research effort, a few initial steps would be helpful to guide further efforts. In particular, it should be straightforward to determine the tradeoff between the local amount of sweep versus the radial extent of sweep, and whether sweep should be in the local chord plane or in some other direction. Efforts should also be made to determine whether aeroelastic tailoring can be combined with sweep to increase favorable torsional components of the flap/lag modes. More comprehensive loads analyses are obviously warranted as part of any design studies.

There are several possible areas of improvement for the CAMRAD II model of the V-22 rotor: details of the grip/yoke model, more sophisticated control system kinematics, and improved aerodynamics models. A few examples are discussed here.

The coupled swashplate model is not exact. Ideally, the extension and rotational (i.e., collective and cyclic) mode shapes should be taken at the transmission adapter, but the transverse mode shapes should be taken from the hub, or if possible from the actual trimmed swashplate location. Another approach would be to explicitly model the nonrotating actuators. Although the kinematic differences would be small, the high sensitivity of whirl-mode damping to control-system kinematics suggests that such an improved model is worth pursuing.
The C81 tables are a major limitation for stability analyses. The area of concern is limited to very high speeds, so the effects on the present research are thought to be negligible. However, establishment of reliable stability trends at high speeds is still desirable and could benefit from improved aerodynamic tables. The key requirement is to generate coefficient data at Mach number increments small enough to guarantee that all significant nonlinear variations are captured. Emerging CFD methodology promises to significantly improve the aerodynamic models needed for whirl-mode predictions.

Very little attention was paid to airframe aerodynamics during this research. It is largely irrelevant for power-off stability, and the existing wing-body aerodynamic tables are adequate for power-on whirl-flutter analyses (Ref. 12). Obvious avenues for future improvements are to generate a comprehensive set of CAMRAD II wing-body tables, or possibly to update the coefficients used by the internal aerodynamic model. Such models will eventually be needed for loads analyses.

\section{Conclusions}

The V-22 was analyzed with CAMRAD II to evaluate whirl flutter in airplane-mode flight. The effects of blade sweep and tip mass offsets on whirl-flutter stability were examined. The rotor was (analytically) destabilized by increasing the magnitude of kinematic pitch-flap coupling $\left(\delta_{3}\right)$ to $-30 \mathrm{deg}$. The outer $20 \%$ of the blade was swept aft a maximum of $30 \mathrm{deg}$ (about one chord length) and the tip balance weight was offset forwards by the same amount. Different combinations of blade sweep and mass offset were evaluated; the most favorable combinations greatly increased the damping of the least stable modes, more than enough to fully stabilize the rotor. A design that combined sweep with an inboard tuning mass represented a more practical design than the most extreme configurations studied; it also proved completely stable with -30 deg $\delta_{3}$. A simple survey of pitchlink loads indicated an increase of $19 \%$ for the worst case.

\section{Acknowledgements}

The author wishes to thank Wayne Johnson for his unfailing support and encouragement for this research, and David A. Popelka for his generous assistance in providing data and advice for modeling the V-22.

\section{References}

1. Kvaternik, R. G., Piatak, D. J., Nixon, M. W., Langston, C. W., Singleton, J. D., Bennett, R. L, and Brown, R. K., "An Experimental Evaluation of Generalized Predictive Control for Tiltrotor Aeroelastic Stability Augmentation in Airplane Mode of Flight," Journal of the American Helicopter Society, Vol. 47, (3), July 2002. 
2. Barkai, S., Rand, O., "The Influence of Composite Induced Couplings on Tiltrotor Whirl-Flutter Stability," Journal of the American Helicopter Snciety, Vol. 43, (2), April 1998.

3. Corso, L. M., Popelka, D., and Nixon, M. W., "Design, Analysis, and Test of a Composite Tailored Tiltrotor Wing," Journal of the American Helicopter Society, Vol. 45, (3), July 2000.

4. Nixon, M. W., Piatak, D. J., Corso, L. M., and Popelka, D. A., "Aeroelastic Tailoring for Stability Augmentation and Performance Enhancements of Tiltrotor Aircraft," Journal of the American Helicopter Society, Vol. 45, (4), October 2000.

5. Acree, C. W., "Rotor Design Options for Improving Tiltrotor Whirl-Flutter Stability Margins," Journal of the American Helicopter Society, Vol. 46, (2), April 2001.

6. Acree, C. W., "Rotor Design Options for Improving V-22 Whirl-Mode Stability," American Helicopter Society 58th Annual Forum Proceedings, Montréal, Quebec, Canada, June 11-13, 2002.

7. Johnson, W., "Influence of Wake Models on Calculated Tiltrotor Aerodynamics," American Helicopter Society Aerodynamics, Acoustics, and Test and Evaluation Technical Specialists' Meeting, San Francisco, California, January 23-25, 2002.

8. Johnson, W., CAMRAD II Comprehensive Analytical Model of Rotorcraft Aerodynamics and Dynamics, Johnson Aeronautics, Palo Alto, California, 2002.

9. Parham, T. and Froebel, A., "V-22 EMD Intermediate Flutter and Divergence Report," Bell-Boeing Report no. 901-910-039, Bell Helicopter Textron, September 1997.

10. Jenks, M. D. and Narramore, J. C., "Final Report for the 2-D Test of Model 901 Rotor and Wing Airfoils (BSWT 592)," Bell-Boeing Report No. D901-99065-1, May 1984, Bell Helicopter Textron.

11. Brunken, J. E. and Vlaminck, R. R., "V-22 MSC/NASTRAN Airframe Vibration Analysis and Correlation," National Technical Specialists' Meeting on Rotorcraft Dynamics, Arlington, Texas, November 1989.

12. Acree, C. W., "A CAMRAD II Model of the V-22 Rotor for Whirl-Flutter Analysis," NASA TM-2003-212262 (in preparation).

13. Parham, T., "V-22 EMD Nonrotating Rotor Ground Vibration Test Report," Bell-Boeing Report No. 901-910052, Bell Helicopter Textron, April 1996.

14. Popelka, D., Sheffler, M., and Bilger, J., "Correlation of Test and Analysis for the 1/5-Scale V-22 Aeroelastic Model," Journal of the American Helicopter Society, Vol. 32, (2), April 1987.
15. Gaffey, T. M., "The Effect of Positive Pitch-Flap Coupling (Negative $\delta_{3}$ ) on Rotor Blade Motion Stability and Flapping," Journal of the American Helicopter Society, Vol. 14, (2), April 1969.

16. Srinivas, V., Chopra, I., and Nixon, M. W., "Aeroelastic Analysis of Advanced Geometry Tiltrotor Aircraft," Journal of the American Helicopter Society, Vol. 43, (3), July 1998.

17. Mayer, R. J., "V-22 Aerodynamics Performance Demonstration: Flight Test Data Report," Bell-Boeing Report No. 901-993-486, Bell Helicopter Textron, 2000.

18. Liu, J. and McVeigh, M. A., "Design of Swept Blade Rotors for High-Speed Tiltrotor Application," AIAA 913147, AIAA, AHS, and ASEE, Aircraft Design Systems and Operations Meeting, Baltimore, Maryland, September 23-25, 1991. 